\title{
Intravenous thrombolisys in basilar dissection: report of a good recovery and follow-up
}

Trombólise endovenosa em dissecção de artéria basilar: relato de boa recuperação e seguimento Gustavo Wruck Kuster ${ }^{1}$, Antonio Claudio Baruzzi², Dimas Ikeoka², Marco Pieruccetti ${ }^{3}$, Valter Furlan²

A 33 year-old man arrived after $3 \mathrm{~h}$ with dysarthria and right-sided hemiparesis (National Institutes Health Stroke Scale (NIHSS:11)). We perform IV thrombolysis and after 1h, NIHSS: 4. After 24h, he presented fluctuating neurological symptoms. Angiography and CT-angio (CTA) (Figures A and B) demonstrated an isolated dissection of the basilar artery, without subarachnoid hemorrhage. Anticoagulation was initiated with rapid improvement. After 7 days he was discharged with NIHSS: 2, Rankin: 2. CTA (Figure C) showed partial basilar recanalization, and after 6 months (Figure D) the basilar artery was normal. Although not considered a formal therapeutic option for arterial dissection ${ }^{1-3}$, IV thrombolysis was performed and maybe prevented microembolic events, improving prognosis $\mathrm{s}^{4.5}$.
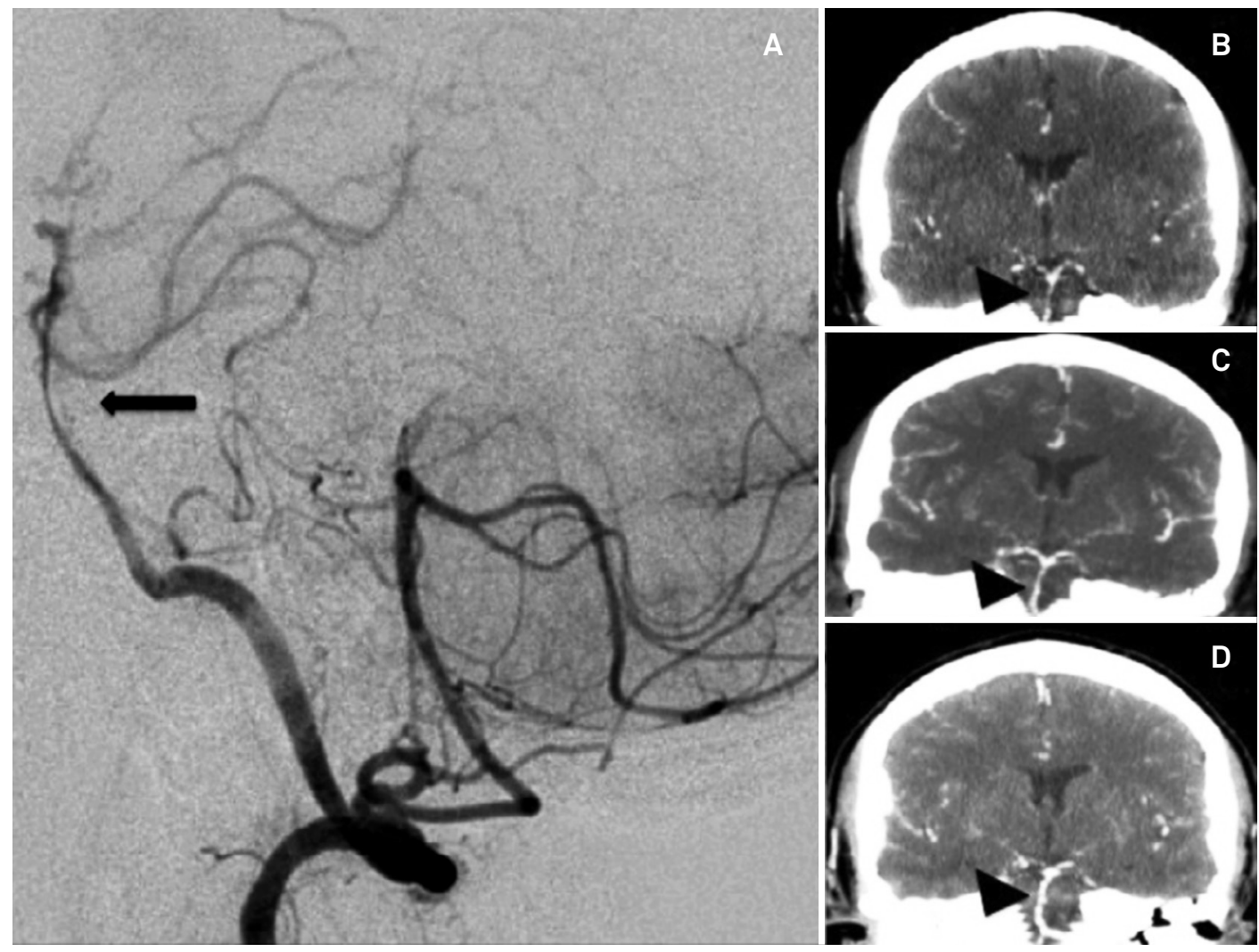

Figure. A) Basilar artery dissection without vertebral artery involvement in Digital Subtraction Angiography - lateral image (arrow). B) CT-angio: Isolated narrowing of basilar artery in day 1 (arrowhead). C) Partial recanalization of basilar artery lumen in day 7 (arrowhead). D) After six months, basilar artery without pseudoaneurysm and improvement of recanalization (arrowhead).

'Neurologist Hospital Total Cor / Hospital Paulistano (Amil Stroke Network);

${ }^{2}$ Cardiologist Hospital Total Cor;

${ }^{3}$ Neurointervencionist Hospital Total Cor/ Hospital Paulistano (Amil Stroke Network).

Correspondence: Gustavo W Kuster; Rua Morgado de Mateus 259 / apto11 / Vila Mariana; 04015-050 São Paulo SP - Brasil; E-mail: gwkuster@hotmail.com Conflict of interest: There is no conflict of interest to declare.

Received 20 May 2013; Received in final form 22 July 2013; Accepted 29 July 2013. 


\section{References}

1. Caplan LR: Dissection of brain-supplying arteries. Nat Clin Pract Neurol 2008;4:34-42.

2. Kim BM, Suh SH, Park SI, et al. Management and clinical outcome of acute basilar artery dissection. Am J Neuroradiol 2008;29:1937-1941.

3. Tognola WA, Centola Filho CA, Chueire RHFM. Dissecção da artéria basilar: relato de caso. Arq Neuropsiquiatr 2000;58:356-359
4.

roste DW, Junker K, Stogbauer F, et al. Clinically silent circulating microemboli in 20 patients with carotid and vertebral artery dissection. Cerebrovasc Dis 2001;12:181-185.

5. Ruecker M, Furtner M, Knoflach M, et al. Basilar artery dissection: series of 12 consecutive cases and review of the literature: Cerebrovasc Dis 2010;30:267-276. 